NBER WORKING PAPER SERIES

A SKEPTICAL NOTE ON THE NEW ECONOMETRICS

\author{
Alan S. Blinder \\ Working Paper No. 1092 \\ NATIONAL BUREAU OF ECONOMIC RESEARCH \\ 1050 Massachusetts Avenue \\ Cambridge MA 02138
}

March 1983

I am grateful to Ray Fair, Mark Machina, Frederic Mishkin, Richard Quandt, Harvey Rosen, Kenneth Small, Robert Solow, Lawrence Summers, and John Taylor for useful suggestions, and to the National Science Foundation for financial support. The research reported here is part of the NBER's research program in Economic Fluctuations. Any opinions expressed are those of the author and not those of the National Bureau of Economic Research. 


\section{A Skeptical Note on the New Econometrics}

\section{ABSTRACT}

One suggestion for coping with the Lucas critique of applied econometric research is to estimate the taste and technology parameters that presumably underlie supply and demand curves. Proponents of this approach generally interpret economy-wide data on prices and quantities as the results of optimization problems solved by representative consumers and firms. Theoretical first-order conditions (normally linear) for interior solutions are then used to convert observed data into estimates of the taste and technology parameters of representative agents.

This brief paper points to a hazard in this type of research. Specifically, the new style of econometrics can lead to serious error if the economy-wide data are not in fact generated by interior optima of representative agents, but rather come from aggregating over agents that behave quite differently.

In an example where the market-wide demand curve is smooth even though each individual's demand function is a step function, the procedures of the new econometrics are shown to lead to grievous errors even though all consumers optimize and the econometrician is assumed to know the precise form of the utility function. It is argued that this example is of quite general applicability, and that the simpler procedures of "old fashioned" econometrics may be less hazardous.

\footnotetext{
Alan S. BIinder Department of Economics Princeton University Princeton, NJ 08544
} 
In an important paper published in 1976, Robert E. Lucas, Ir. offered an insightful and stunning critique of what were then standard econometric practices. The critique took the profession by storm, and econometricians--or at least macro-econometricians-have been struggling with the problem of how to reconstruct econometrics ever since. ${ }^{I}$ In this brief paper, I argue that one of the major approaches that has been developed for dealing with the Lucas critique may introduce errors of its own into econometric estimates--errors that may well be more serious in practice than those pointed to by Lucas.

The Old Econometrics and the Lucas Critique

I begin with an example that briefly characterizes the way econometrics was done before Lucas, and illustrates why Lucas (correctly) claimed that these procedures might lead to error.

Consider the problem of estimating a supply curve and a demand curve for a single market, as depicted in Figure 1. Econometricians used to conceptualize the inference problem as follows. For each time period we have a pair of observations on price and quantity $\left(p_{t}, x_{t}\right)$, which we interpret as the intersection of the demand curve $D$ and the supply curve $S$ (point $E$ ). If there are one or more shift variables that affect the demand curve but not the supply curve, and one or more shift variables that affect the supply curve but not the demand curve, then

$I_{\text {The Lucas critique is just as applicable to microeconomics }}$ as to macroeconomics. However, it seems that mostly macroeconometricians have worried about it. 
$1 a$.

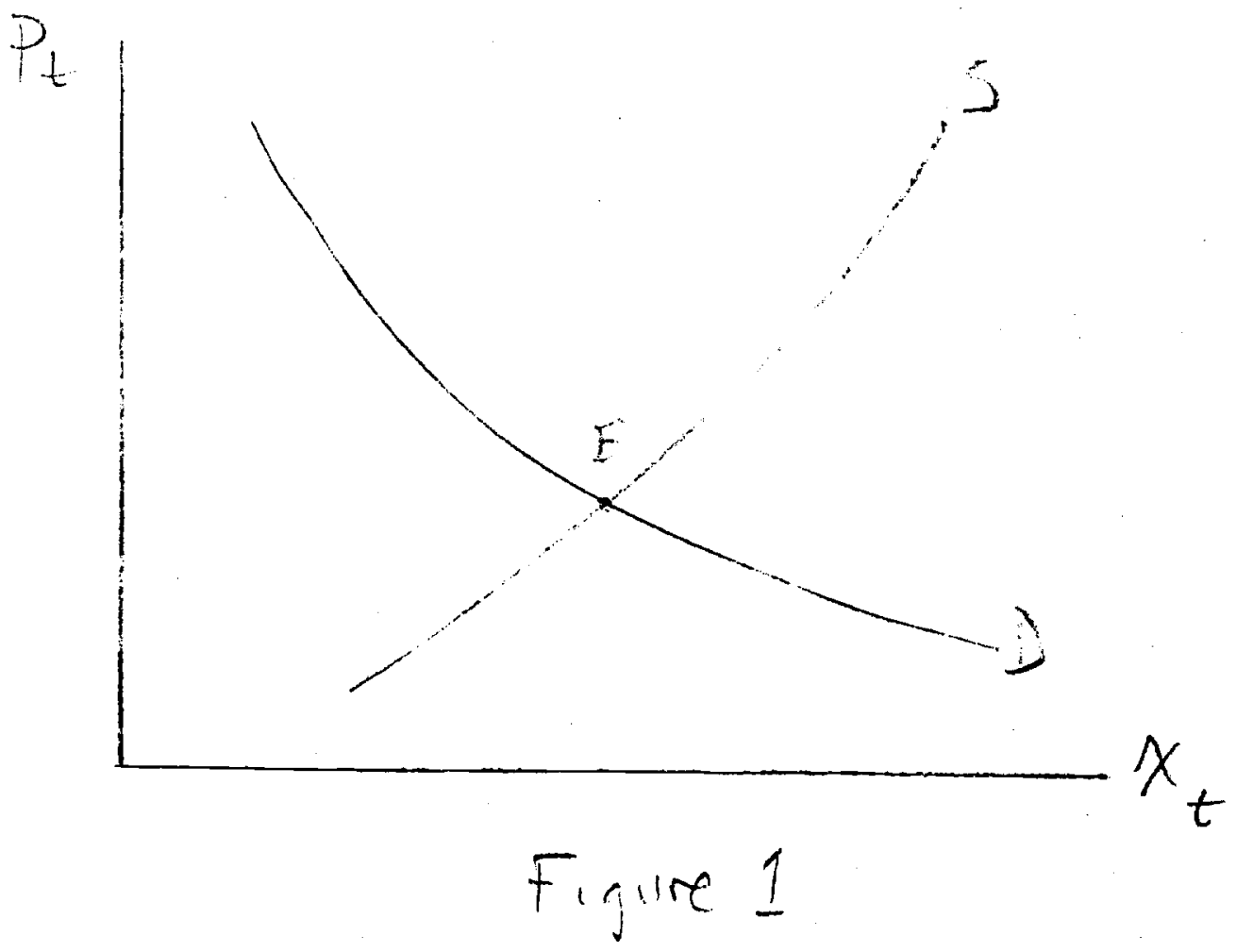


standard procedures can be used to estimate the slopes of these two curves.

Why, apart from the general quest for knowledge, would we want to estimate such parameters? There are many possible reasons. One which seems germane to the issue raised by Lucas is that the government might be considering regulating the supply of the commodity, and would like to estimate the changes in price and quantity that would result. The standard procedures in the "old econometrics" would be to estimate the parameters of the demand curve (say, by two stage least squares) and then use these estimates to predict behavior. Essentially, this amounts to extrapolating past patterns of behavior into the future.

Enter the Lucas critique. Lucas argued, quite correctly, that the supply and/or demand curves observed in the past might change if there were a change in the economic environment (e.g., in government policy). For example, suppose a demand curve had been estimated on data from a period during which the government set the price $\left(\mathrm{p}_{t}\right)$ exogenously, and the econometric estimate was:

$$
\text { (I) } x_{t}=a-b p_{t}+c y_{t} \text {, }
$$

where $y_{t}$ is income. But suppose the estimate of b really combined the true demand slope and an expectational parameter. For example, suppose the "true" demand curve was:

$$
\text { (2) } x_{t}=a-\beta_{1} p_{t}+\beta_{2}\left(p_{t+1}\right)+\gamma y_{t}+\varepsilon_{t}
$$

where $t^{P_{t+1}}$ denotes the (rational) expectation of next period's 
price. If prices during the period of observation had followed the stochastic process:

$$
\text { (3) } \quad p_{t}=A+\rho p_{t-1}+w_{t}
$$

where $w_{t}$ is a white noise error term, then the (rational) expected future price would be $\rho \mathrm{p}_{t}$, leading to the observed demand rule:

$$
\text { (4) } x_{t}=\alpha-\left(\beta_{1}-\beta_{2}\right) A-\left(\beta_{1}-\beta_{2}\right) p_{t}+\gamma_{t} y_{t}+\varepsilon_{t} \text {. }
$$

Comparing (4) with (1), we see that a and b are really estimates of $\alpha-\left(\beta_{1}-\beta_{2}\right) A$ and $B_{1}-\rho B_{2}$, respectively, and therefore should change if the stochastic process generating prices changes. The upshot of this observation is that the estimates of $a$ and $b$ derived from the historical data might be inappropriate if the policy rule changes. Put differently, extrapolations of past demand behavior might systematically err.

\section{The New Econometrics}

Several approaches have been suggested for dealing with the Lucas critique. One is to introduce directly observed expectational variables into our equations, rather than using standard observable variables to "proxy" expectations (as, for example, $\mathrm{p}_{\mathrm{t}}$ proxied in part for $t^{\mathrm{P}_{t+1}}$ ). It is in this spirit that several scholars have suggested estimating investment spending as a function of "Tobin's q" rather than as a function of directly observed variables such as interest rates and tax parameters. ' I take this

${ }^{1}$ See Abel (1980), Blanchard (1980), or Summers (1981). 
to be the best possible approach where it is feasible. Unfortunately, most expectational variables are not directly observed.

A second approach is to impose, in estimation, the crossequation constraints suggested by rational expectations. ${ }^{1}$ For example, we could try to estimate jointly equations (2) and (3), taking account of the fact that ${ }_{t} \mathrm{p}_{t+1}=\rho \mathrm{p}_{t}$.

A third approach, and the one I want to take issue with here, is to go "beyond demand and supply curves" (in Sargent's (1982) words) and try to estimate the taste and technology parameters that, according to neoclassical equilibrium theory, underlie them. ${ }^{2}$

As I interpret this third approach, the suggestion is no longer to think of our data as coming from Figure I's supply and demand curves, but rather as coming from Figure 2, where I depict an indifference curve for the representative consumer and a transformation curve for the representative firm. Here we see the consumer's and the producer's choices between two goods, $x_{1}$ (which is the numeraire) and $\mathrm{x}_{2}$; the relative price, $\mathrm{P}_{t}$, appears as the slope of the tangent line at point $E$. Whereas in the old econometrics we would have taken data on $x_{2 t}$ and $P_{t}$ and tried to estimate the slopes of the supply and demand curves, the new econometrics tries to use these same data to estimate the slopes of the indifference and transformation curves--the "taste and technology parameters."

${ }^{1}$ For an example, see Taylor (1979).

${ }^{2}$ It should be pointed out that the three approaches are by no means mutually exclusive. 
The program of the new econometrics is beyond reproach in principle. The issue is whether or not we can really expect to carry it out successfully. What are some of the pitfalls of which we must beware? To be specific, I will focus on one particular class of reasons why the methods advocated by Hansen and Sargent (1980) and others may err systematically--and by gross amounts.

The reason is quite simple and general: much of the time series data we get on prices and quantities may not reflect neoclassical equilibria of the sort depicted in Figure 2. Two instances seem to me to be of great empirical importance. First, many of the price-quantity combinations we observe may reflect disequilibria rather than equilibria. It is by now well known that imposing the (false) hypothesis of equilibrium in such cases may, but need not always, lead to grievous errors. I second, many of the equilibria attained by even rational and well-informed optimizing agents may be corners rather than nice tangencies such as point $E$ in Figure 2. The next section illustrates this problem with a specific example, and suggests that the errors introduced by forcing the data into the Procrustean bed of Figure 2 might be enormous.

\section{An Example}

Consider a consumer allocating his total income, $y$, between two goods. $x_{1}$ is the numeraire and is infinitely divisivle. $x_{2}$ has a price of $\mathrm{p}$, but consumers can only choose between buying 


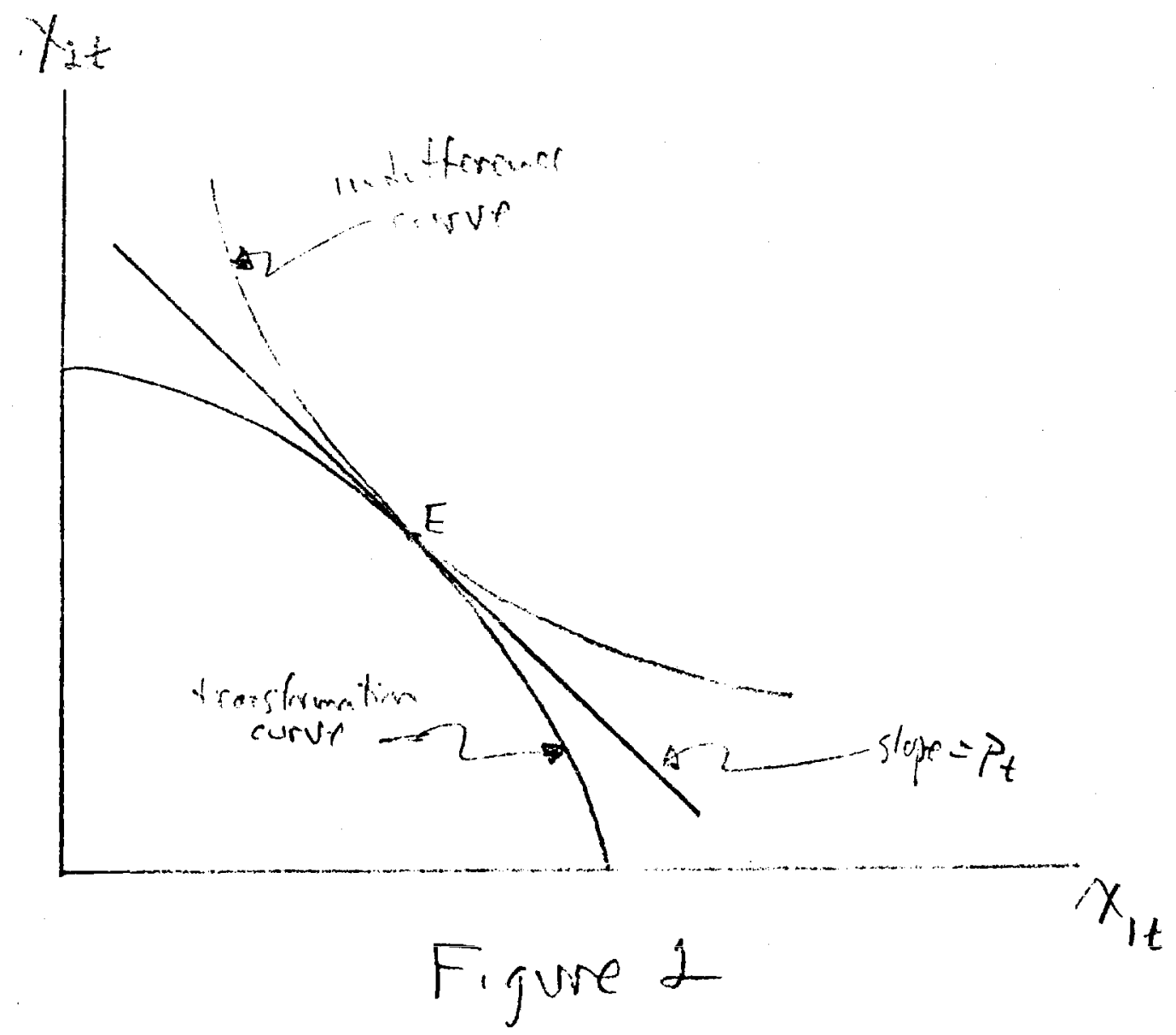


it $\left(x_{2}=1\right)$ or not buying it $\left(x_{2}=0\right)$. There are many examples of goods that $x_{2}$ might represent, and $I$ think the general phenomenon is very important. For many glods, the primary reason for a downward sloping market demand curve may be that more people drop out of the market as the price rises, not that each individual consumer reduces his purchases. (Think, for example, of books, furniture, cars, houses, movie tickets.) I Another importent application might be labor supply, with $x_{2}$ interpreted as the fraction of time devoted to leisure and $\mathrm{p}$ interpreted as the real wage.

The consumer's "budget constraint" is:

$$
\text { (5) } \mathrm{x}_{1}+\mathrm{px}_{2}=\mathrm{y} \text {, }
$$

but his only real choice is between $\left(x_{2}=0, x_{1}=y\right)$ and $\left(x_{2}=1, x_{1}=y-p\right)$. ( $I$ assume $y>p$ to make this problem meaningful.)

To create a simple example, assume that every consumer has a Stone-Geary utility function:

$$
\text { (6) } U\left(x_{1}, x_{2}\right)=\log \left(1+x_{1}\right)+\alpha \log \left(1+x_{2}\right)
$$

where $\alpha$ is a taste parameter that differs across individuals. The consumer's optimization problem is easily solved, but not

${ }^{1}$ Clearly the length of the period is critical here. If we take the lifetime as the time unit, then discrete purchases are probably not terribly important for most commodities. But the data we work with are generally monthly, quarterly or annual. Over these time periods, discrete choice is probably quite important. some of the relevant theory is displayed in Novshek and Sonnenschein (1979). 
by calculus. If he buys $x_{2}$, his utility is:

$$
\log (1+y-p)+\alpha \log (2),
$$

whereas if he does not buy $x_{2}$, his utility is:

$$
\log (1+y) \text {. }
$$

He therefore will buy $\mathrm{x}_{2}$ if and only if:

$$
\text { (7) } \alpha>\frac{\log (1+y)-\log (1+y-p)}{\log 2} \text {. }
$$

To generate a downward-sloping market demand curve from the individual demand curves that are step functions, define the righthand side of (7) as $\alpha^{*}$, which depends on $y$ and $p$. To keep the example simple, assume that $\mathrm{y}$ is the same for everyone, and let $f(\alpha)$ be the density function of the taste parameter $a$. Then market demand is:

$$
\text { (8) } x_{2}(p, y)=\int_{\alpha *(y, p)} f(\alpha) d \alpha=1-F(\alpha *(y, p)) \text {. }
$$

where $F(\cdot)$ is the cumulative distribution function corresponding to $f(\cdot)$. Notice that the price and income derivatives of the demand function are:

$$
\begin{aligned}
& \frac{\partial x_{2}}{\partial p}=-f\left(\alpha^{*}\right) \frac{\partial \alpha^{*}}{\partial p}=\frac{-f\left(\alpha^{*}\right)}{(1+y-p) 10 g^{2}}<0, \\
& \frac{\partial x_{2}}{\partial y}=-f\left(\alpha^{*}\right) \frac{\partial \alpha^{*}}{\partial y}=\frac{p f\left(\alpha^{*}\right)}{\log 2(1+y)(1+y-p)}>0,
\end{aligned}
$$


where I have used the definition of $\alpha *(\mathrm{p}, \mathrm{y})$ in taking the derivatives. The market dinand function is thus well behaved: it is increasing in income and decreasing in price.

What would an econometrician practicing the new econometrics do in this case? So as not to becloud the issue, assume that he gets the utility function exactly right. ${ }^{1}$ His only error, I assume, is that he mistakenly interprets the market demand curve as a blowup of the individual demand curve of a representative consumer, not realizing that $x_{2}$ is available only in discrete amounts. That is, he erroneously interprets the price and quantity data as reflecting tangencies between indifference curves and budget lines as in Figure 2.

The hypothetical representative consumer would then maximize:

$$
\log \left(1+X_{1}\right)+a \log \left(1+X_{2}\right)
$$

subject to budget constraint (5), yielding the following demand curve for $\mathrm{x}_{2}$ :

$$
\text { (9) } x_{2}=\frac{a}{1+a}\left(\frac{1+y}{p}\right)-\frac{1}{1+a} \text {. }
$$

Following the program suggested by Sargent and others, he would then use data on $y, p$, and $x_{2}$ along with equation (9) to infer the value of the taste parameter a. What would he get?

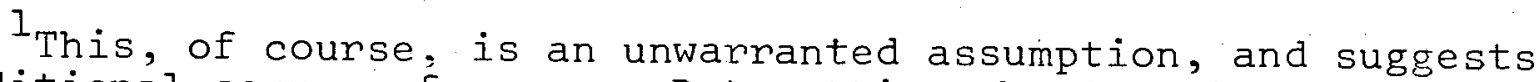
an additional source of error. But getting the functional form right is always a problem in any style of econometric work. 
It is convenient to define a synthetic variable:

(10) $\mathrm{z}_{t}=\frac{1+\mathrm{y}_{\mathrm{t}}}{\mathrm{P}_{\mathrm{t}}}$.

Then (9) can be written as the simple linear regression:

( $\left.g^{\prime}\right) x_{2 t}+1=A\left(z_{t}+1\right)$,

where $A \equiv a /(I+a)$. The ordinary least squares estimator of this single parameter has probability limit:

(II) $\operatorname{plim} \hat{A}=\frac{\operatorname{cov}\left(x_{2}, z\right)}{\sigma_{z}^{2}}$.

Let us assume that the true model is as indicated earlier, and that it holds without error. A computationally convenient case arises when the tase parameter a has the following exponential density:

$$
f(\alpha)=\lambda e^{-\lambda \alpha} \quad \alpha \geq 0
$$

with $\lambda=\log 2$. (So the mean of $\alpha$ is $1 /(\log 2) \approx 1.44$. ) In this case, it turns out that the true demand curve, equation ( 8 ), has the simple form:

$$
\text { (8') } x_{2 t}=1-\frac{1}{z_{t}} \text {, }
$$

where $z_{t}$ is defined in ( 10$)$. From ( $\left.8^{\prime}\right)$, the covariance needed for (II) is seen to be:

$$
\operatorname{cov}\left(X_{2}, Z\right)=\bar{Z} E\left(\frac{I}{Z}\right)-I \text {, }
$$

which is necessarily positive by Jensen's inequality.

To take this calculation further, use the second-order Taylor series approximation for $\mathrm{I} / \mathrm{Z}$ around the point $\mathrm{Z}=\overline{\mathrm{z}}$, viz.:

$$
\frac{I}{\bar{Z}} \doteq \frac{I}{\bar{Z}}-\frac{I}{(\bar{Z})^{2}}(\mathrm{Z}-\overline{\mathrm{Z}})+\frac{1}{(\overline{\mathrm{Z}})^{3}}(\mathrm{z}-\overline{\mathrm{Z}})^{2} .
$$


Taking expectations gives:

$$
E\left(\frac{1}{\mathrm{Z}}\right) \doteq \frac{1}{\overline{\mathrm{Z}}}\left[1+\left(\frac{{ }_{\mathrm{Z}}}{\overline{\mathrm{Z}}}\right)^{2}\right],
$$

so that (11) becomes simply:

$$
\text { (II') } \operatorname{plim} \hat{A} \doteq \frac{1}{(\bar{Z})^{2}} \text {. }
$$

This would be the estimated "slope" of the demand curve with respect to $Z$ derived by the procedures of the new econometrics. It is to be compared with the true slope which, according to $\left(8^{\prime}\right)$ is:

(12) $\frac{\partial X_{2}}{\partial z}=\frac{1}{z^{2}}$.

At the mean $Z$ (which is not the mean $y$ and $p$ ), these slopes are equal. But at a value of $z$ that is, say, twice the mean--which is not at all unusual in time series data--the estimated slope would be four times too large. Huge errors seem likely.

Notice also that the econometric procedures based on the false assumption of interior maxima badly distort the shape of the true demand function. For example, the estimated demand curve would be thought to be linear in income and convex in price:

$$
\frac{\partial^{2} x_{2}}{\partial y^{2}}=0 ; \quad \frac{\partial^{2} x_{2}}{\partial p^{2}}=2 \hat{A}(I+y) p^{-3}>0
$$

whereas in fact the true demand curve is concave in income and linear in price:

$$
\frac{\partial^{2} x_{2}}{\partial y^{2}}=-2 p(I+y)^{-3}<0, \frac{\partial^{2} x_{2}}{\partial p^{2}}=0
$$


Figure 3 charts the actual and estimated demand curves as a function of $Z$ in the case of $\bar{Z}=2$ (which corresponds to $A=\frac{1}{4}$ ).

In this example, which I do not believe is contrived in any sense except, of course, its reliance on discrete choice, the potential errors in pursuing the new econometrics are enormous. It would take a lot of persuasion--and some evidence--to convince me that the problem isolated by Lucas typically leads to errors of this magnitude.

Two responses can be made to this example. The first notes that my example is just a case of specification error, and everyone knows that misspecification can lead to bad estimates. For example, if the econometrician understood the discrete nature of the choice problem, he would have estimated ( $\left.8^{\prime}\right)$ instead of ( 9 ) and would not have made a mistake.

Naturally, this is so. I presume that maximum likelihood estimation of the correct model always leads to the best estimates; the trick is to find the correct model. My point is that the particular procedures advocated by the new econometricians invariably view the data as being generated by interior solutions to optimization problems solved by representative individuals and firms. My example shows that, if this view of the world is wrong, huge errors can result. I claim further that discrete choice and differences in tastes are pervasive phenomena, so the example is not some pathological case but is illustrative of a wide class of problems. 
IIa.

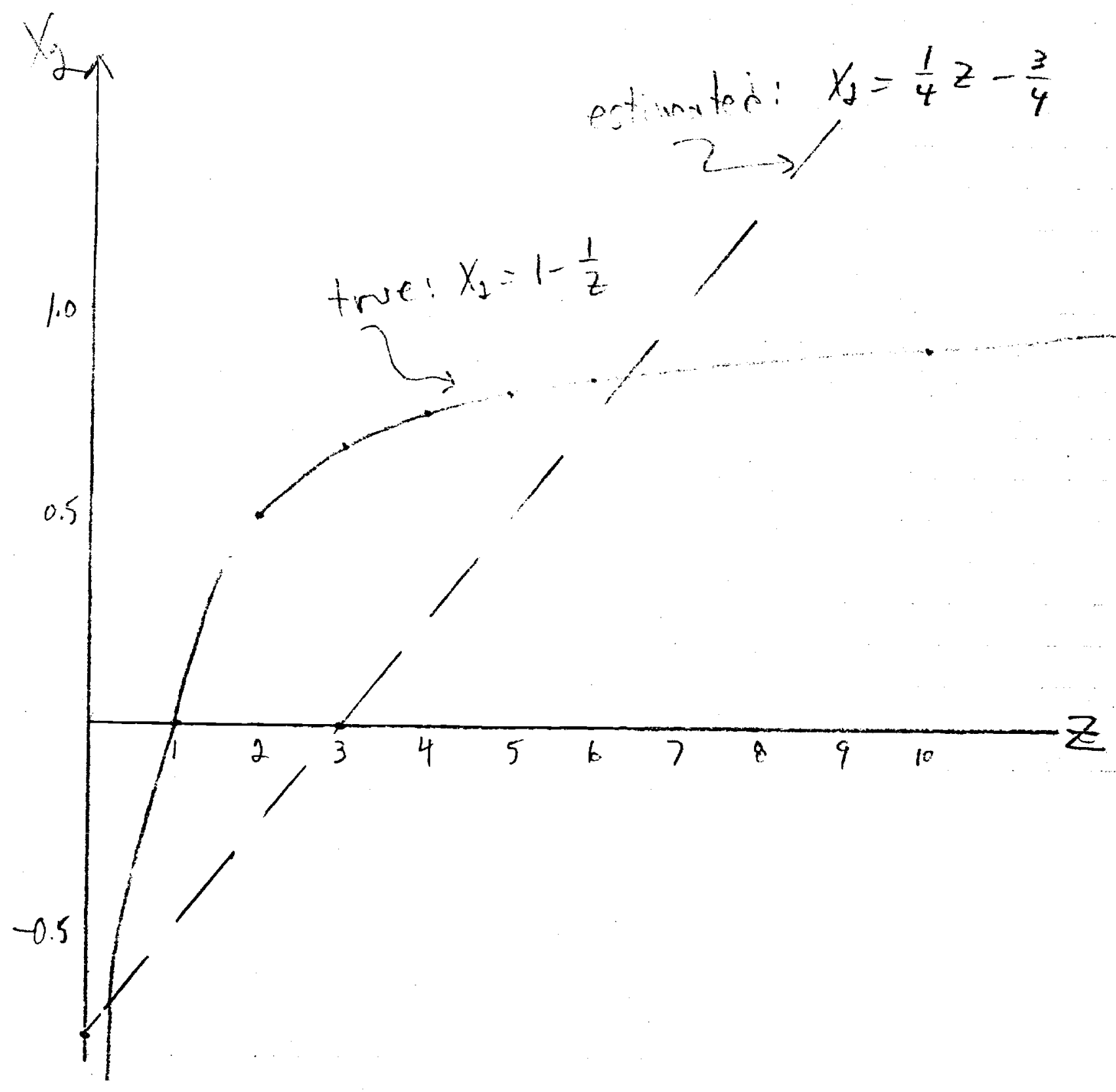

Figure 3 
Two examples are worth mentioning in this context. ( I am sure there are many others.) The first has to do with taste parameters. Christensen, Jorgenson, and Lau (1975) used a very flexible functional form, but still rejected the hypothesis that the aggregate data could have been generated as the solution to a utility maximization problem. The second involves technology parameters. Blinder (1981) showed that the $(S, S)$ model of inventory behavior can be aggregated to lead to an equation that looks just like a stock adjustment model. In the stock adjustment interpretation of the equation, which car: be derived from a linear-quadratic structure similar to that used by Hansen and Sargent, ${ }^{1}$ the coefficient on the initial inventory stock reflects certain "technology parameters." However, under the $(S, S)$ interpretation of the same equation, this coefficient arises from the aggregation process and has nothing whatsoever to do with technology. If the $(S, s)$ model is true, the procedures of the new econometrics would mistakenly "identify" the "technology parameters" of a quadratic cost function when, in fact, no such function exists.

The second response recalls that the advantage of having an estimator which is immune to the Lucas critique only comes to the fore when there is a regime change. If the environment remains the same, then even reduced form parameters passing themselves off as "structural" will be invariant. But only taste and technology parameters will remain invariant in the face of large changes in regime.

${ }^{1}$ See Blinder (1982). 
I have two answers to this. First, it seems to me that we rarely experience major, abrupt regime changes where Lucas-type reasoning leads us to expect sudden, large changes in parameters. ${ }^{1}$ For workaday econometrics, the kinds of estimation errors illustrated by my example may be quite large relative to those introduced by ignoring the Lucas critique.

Second, let us use the example to examine the chief selling point of the new econometrics: that it can handle regime changes better because it yields estimates of taste and technology parameters. In the example, the taste parameters are summarized by an exponential distribution of the taste parameter $\alpha$, whose mean is $1 / \log 2 \doteq 1.44$. The new econometric procedures would yield a single taste parameter: the "a" in the utility function of the representative consumer, which it would use to predict behavion following a change of regime. Since the point estimate of $A=a /(I+a)$ has $(\bar{Z})^{-2}$ as its probability limit, the plim of a is:

$$
\operatorname{plim} a=\frac{1}{(\bar{Z})^{2}-1}
$$

Depending on the precise value of $\bar{Z}$, this may or may not bear much resemblance to the mean value of $\alpha$ in the population, For example, in the $\bar{Z}=2$ case depicted in Figure 3 , plim $a=1 / 3$, which is less than one quarter of the true population mean!

$I_{\text {Sims }}(1982)$ shares this view. 
There is thus no reason to think that the "taste and technology parameters" derived from the new econometrics will be good guides to what actually happens following a regime change (unless, of course, we really get the model right).

\section{In Conclusion}

This short paper should not be misinterpreted as a brief against rational expectations, nor even against imposing the crossequation constraints delivered by rational expectations in applied econometric work. The criticisms of the old econometrics made by Lucas, Sargent and others are not wrong; they are absolutely correct. The paper is, however, a brief against the view that there is any one "right way" to do econometrics. In statistical work with dirty data, there is no room for purity and no such thing as a free lunch. The applied econometrician who single-mindedly devotes his energies to coping with the Lucas critique is Iikely to be blind-sided by another problem.

Saying this in no way denies the validity of the Lucas critique, but merely points out that it may not always be of great empirical importance. In my view, the critique should take its place as one among many serious problems that confront the applied econometrician --on a par, perhaps, with violations of the assumptions of the GaussMarkov theorem. The realization, for example, that least squares bias can always be present has not stopped applied econometrics in its tracks (though it has given cause for humility). Perhaps the Lucas critique should be treated in the same way. 
This broader perspective dictates that we follow a more pragmatic, case by case, approach in which we recognize that other problems may be more important than the Lucas critique in particular cases. Certainly, there is no a priori reason to suppose that the best econometric estimates are those that are most immune to the Lucas critique if the procedures employed to deal with the critique introduce errors of their own.

Specifically, the example in this paper suggests that the new econometrics--which views the world as composed of concave consumers and concave firms that compute mathematical expectations and meet atomistically in blissful equilibrium along separating hyperplanes-is potentially fraught with error. Using these techniques to go "beyond supply and demand curves" to the taste and technology parameters that presumably underlie them may be a high-risk strategy. And in many cases we may conclude that, the Lucas critique notwithstanding, extrapolating supply and demand curves based on past behavion is the best technique we have for predicting the future. 


\section{REFERENCES}

Andrew B. Abel, "Empirical Investment Equations: An Integrative

Framework," in K. Brunner and A. H. Meltzer (eds.), On the State of Macroeconomics, Carnegie-Rochester Conference

Series vol. 12 (Amsterdam: North-Holland), 1980.

Olivier J. Blanchard, "The Monetary Mechanism in the Light of Rational Expectations," in S. Fischer (ed.), Rational

Expectations and Economic Policy (Chicago: University of (hicago Press), 1980.

Alan S. Blinder, "Retail Inventory Behavior and Business Fluctuations," Brookings Papers on Economic Activity, 2, 1981, Pp. 443-505. , "Inventories and Sticky Prices: More on the

Microfoundations of Macroeconomics," American Economic Review,

72 (June 1982), pp. 334-348.

Laurits R. Christensen, Dale W. Jorgenson, and Lawrence J. Lau, "Transcendental Logarithmic Utility Functions," American Economic Review, 65 (June 1975), pp. 367-383.

Lars Peter Hansen and Thomas J. Sargent, "Formulating and Estimating Dynamic Linear Rational Expectations Models," Journal of Economic Dynamics and Control, 1980 .

Robert E. Lucas, Jr., "Econometric Policy Evaluation: A Critique," Journal of Monetary Economics, vol. 2, January 1976 (supplement), pp. 19-46.

William Novshek and Hugo Sonnenschein, "Marginal Consumers and Neoclassical Demand Theory," Journal of Political Economy, vol. 87, No. 6, December 1979, pp. 1368-1376. 
Harvey S. Rosen and Richard E. Quandt, "Estimation of a Disequilibrium Aggregate Labor Market," The Review of Economics and Statistics, vol. LX, No. 3, August 1978, pp. $371-379$.

Thomas J. Sargent, "Beyond Demand and Supply Curves in Macroeconomics," American Economic Review, May 1982.

Christopher Sims, "Policy Analysis with Econometric Models," Brookings Papers on Economic Activity, 1, 1982.

Lawrence H. Summers, "Taxation and Corporate Investment: A q-Theory Approach," Brookings Papers on Economic Activity, 1, 1981, pp. 67-127.

John B. Taylor, "Estimation and Control of a Macroeconomic Model with Rational Expectations," Econometrica, vol. 47, 1979. 